\title{
Irradiation Induced Phenomena in Nuclear Glass
}

\author{
Jean-Marc DELAYE ${ }^{1}$, Dimitrios KILYMIS ${ }^{2}$, Le-Hai KIEU ${ }^{1}$, Sylvain PEUGET ${ }^{1}$ \\ ${ }^{1}$ CEA-DEN-DTCD, Service d'Etudes et Comportement des Matériaux de Conditionnement, SECM (Marcoule, France) \\ ${ }^{2}$ Laboratoire Charles Coulomb UMR 5221, Université de Montpellier-CNRS (Montpellier, France)
}

\section{Introduction}

In France, non-recoverable radioactive wastes coming from spent nuclear fuels are stored in alumino borosilicate glassy matrices. It is envisaged to store them in a deep geological repository to isolate them from the rest of the environment. These glasses will be subjected to internal irradiations, and after some hundreds of years, to water corrosion due to the arrival of the groundwater in contact with them. Studies are carried out to quantify the radiation and water corrosion effects to characterize the long-term waste package behavior. Experimental and numerical approaches have been considered in order to study the variations of the structural and mechanical properties under irradiation.

Experimentally, it has been shown, on industrial and simplified glasses doped with short lived actinides or irradiated externally by heavy ions, that the elastic effects lead to different structural (decrease of the polymerization glass networks, increase of the disorder) and mechanical modifications (swelling, decrease of the hardness, increase of the fracture toughness, increase of the internal energy). A computational approach using classical molecular dynamics has been developed in parallel to clarify the correlations between the structural and mechanical property changes. This presentation will expose the main results from our simulations.

\section{Computational method}

An empirical pair potential of the Buckingham form has been developed recently to model atomic interactions [1]. Hence the interaction between any $(i, j)$ pair of constituent atoms is modelled using the following relation:

$$
\Phi\left(r_{i j}\right)=\frac{q_{i} q_{j}}{r_{i j}}+A_{i j} \exp \left(-\frac{r_{i j}}{\rho_{i j}}\right)-\frac{c_{i j}}{r_{i j}^{6}}
$$

The adjustable parameters have been determined in order to reproduce structural and elastic properties of a set of $\mathrm{SiO}_{2}-\mathrm{B}_{2} \mathrm{O}_{3}-\mathrm{Na}_{2} \mathrm{O}$ glasses. A dependence between the ionic charges and the glassy compositions has been introduced in order to reproduce the Boron anomaly, i.e. the nonlinear evolution of the $B$ coordination versus the $R\left(=\left[\mathrm{Na}_{2} \mathrm{O}\right] /\left[\mathrm{B}_{2} \mathrm{O}_{3}\right]\right)$ and $\mathrm{K}\left(=\left[\mathrm{SiO}_{2}\right] /\left[\mathrm{B}_{2} \mathrm{O}_{3}\right]\right)$ ratios. These potentials were then used to study fracture mechanisms and nanoindentation in pristine and irradiated simplified nuclear glasses.

\section{Results}

The three simulated glass compositions are the following:

SBN12 glass: $59.6 \% \mathrm{SiO}_{2}-28.2 \% \mathrm{~B}_{2} \mathrm{O}_{3}-12.2 \% \mathrm{Na}_{2} \mathrm{O}$

SBN14 glass: $67.8 \% \mathrm{SiO}_{2}-18.0 \% \mathrm{~B}_{2} \mathrm{O}_{3}-14.2 \% \mathrm{Na}_{2} \mathrm{O}$, this glass is characterized by the same molar ratios as the real nuclear glass

SBN55 glass: $55.3 \% \mathrm{SiO}_{2}-14.7 \% \mathrm{~B}_{2} \mathrm{O}_{3}-30.0 \% \mathrm{Na}_{2} \mathrm{O}$

For each glassy composition, pristine structures (quenched from the liquid state with a rate equal to $5 \times 10^{12} \mathrm{~K} / \mathrm{s}$ ) and disordered structures have been prepared. The disordered structures have been obtained after the heating of the pristine ones and their faster quench (with a rate equal to $10^{14} \mathrm{~K} / \mathrm{s}$ ) in order to reproduce the main radiation effects, i.e. depolymerization and increase of the internal 
disorder. The disordered glasses are considered as models of irradiated ones and their mechanical properties have been compared to those of the pristine glasses.

The fracture simulations have made possible to identify the different steps leading to the cracking of the materials [2]. Under the application of an external tensile stress, nano cavities are firstly formed. Then they begin to coalesce as the external stress increases forming increasingly large voids until the complete opening of the structure. During the fracture process, two different behaviors have been noticed: the $\mathrm{Si}$ and 4-coordinated $\mathrm{B}$ atoms on one hand accumulating stresses in their local environments, and, on the other hand, the 3-coordinated $\mathrm{B}$ and $\mathrm{Na}$ atoms adapting themselves much more easily to the local stress changes and then facilitating the viscous flow. This observation has made possible to propose an explanation of the origin of the fracture toughness increase in the simplified SBN14 glass. The radiation effects induce a decrease of the average B coordination, with a rise of the 3-coordinated $B$ concentration. In consequence, the plasticity of the material increases, and the energy cost needed for the sample breakage is larger, hence the fracture toughness increase.

Concerning the nanoindentation simulations [3], a Vickers indenter in diamond has been pushed then removed from a simulation box and, using the loading - unloading curves, the hardness values have been quantified (Fig. 1). With the increase of the disorder, a systematic hardness decrease is observed [4] in the three glassy compositions that has been correlated to an increase of the 3coordinated $\mathrm{B}$ and non-bridging oxygen concentrations.
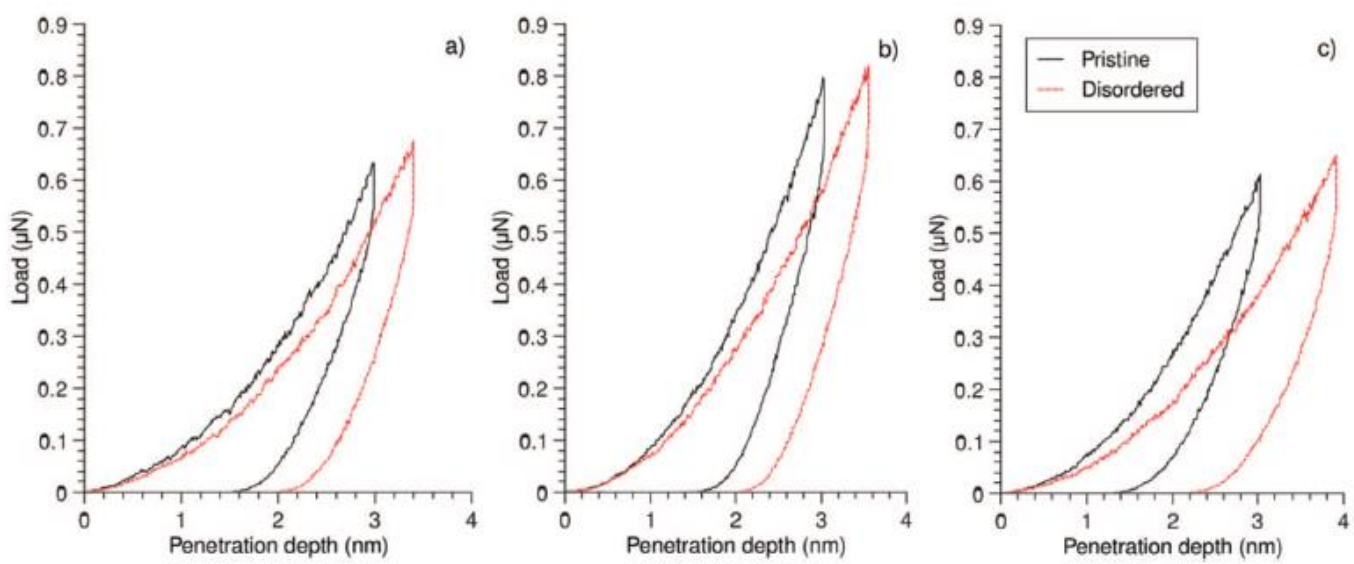

Fig. 1: Loading - unloading curves during nanoindentation simulated in the SBN12 (a), SBN14 (b) and SBN55 (c) glasses.

Taking into account the disordering and depolymerization effects, this study using the classical molecular dynamics method has therefore allowed reproducing changes of the mechanical properties analogous to what has been observed in simplified nuclear glasses irradiated externally by heavy ions. Thus, the structural origins of these changes have been better understood.

\section{References}

[1] L.-H. Kieu, J.-M. Delaye, L. Cormier, C. Stolz, "Development of empirical potentials for sodium borosilicate glass systems", J. Non-Cryst. Solids 357 (2011) 3313.

[2] L.-H. Kieu, J.-M. Delaye, C. Stolz, "Modeling the effect of composition and thermal quenching on the fracture behavior of borosilicate glass", J. Non-Cryst. Solids 358 (2012) 3268.

[3] D. A. Kilymis, J.-M. Delaye, "Deformation mechanisms during nanoindentation of sodium borosilicate glasses of nuclear interest", J. Chem. Phys., 141 (2014) 014504.

[4] D. A. Kilymis, J.-M. Delaye, "Nanoindentation studies of simplified nuclear glasses using molecular dynamics", J. Non-Cryst. Solids 401 (2014) 147. 


\title{
Irradiation Induced Phenomena in Nuclear Glass
}

\author{
Contributors \\ J.-M. Delaye, D. Kilymis, L.-H. Kieu, S. Peuget
}

Service d'Etudes et Comportement des Matériaux de

Conditionnement (SECM), CEA Marcoule, France 


\section{OUTLINE}

Context: Analogy between the behaviors of complex and simplified nuclear glasses under irradiation (ballistic effects)

Classical molecular dynamics simulations

- Empirical potentials

- Series of displacement cascades

- Fracture: origin of the fracture toughness increase under irradiation

- Hardness: origin of the hardness decrease under irradiation

Conclusions 


\section{R7T7 glass: the French nuclear glass to confine the high level radioactive wastes}

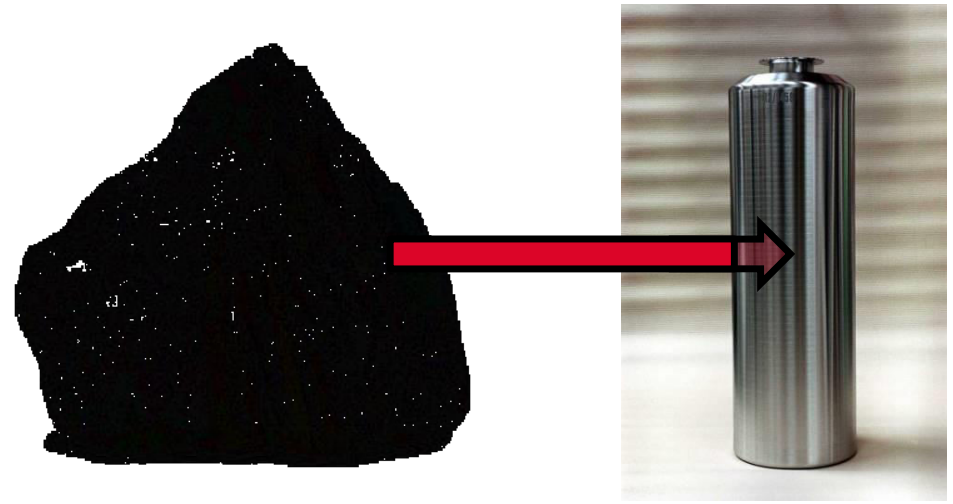

Borosilicate R7T7 glass

- The nuclear glasses will be subjected to internal irradiations ( $\alpha$ disintegrations from minor actinides and $\beta / \gamma$ radiations from fission products)

- It's important to understand the radiation effects on the macrocopic properties to certify the long term behavior of the glass
R7T7 glass composition: more than 30 components

\begin{tabular}{|c|c|}
\hline & $\begin{array}{c}\text { Composition } \\
\text { nominale }\end{array}$ \\
\hline & \\
\hline $\mathrm{SiO}_{2}$ & 45,1 \\
$\mathrm{~B}_{2} \mathrm{O}_{3}$ & 13,9 \\
$\mathrm{~A}_{2} \mathrm{O}_{3}$ & 4,9 \\
$\mathrm{Na}_{2} \mathrm{O}$ & 9,8 \\
$\mathrm{CaO}$ & 4,0 \\
$\mathrm{Fe}_{2} \mathrm{O}_{3}$ & 2,9 \\
$\mathrm{NiO}$ & 0,4 \\
$\mathrm{Cr}_{2} \mathrm{O}_{3}$ & 0,5 \\
$\mathrm{P}_{2} \mathrm{O}_{5}$ & 0,3 \\
$\mathrm{Li}_{2} \mathrm{O}$ & 2,0 \\
$\mathrm{ZnO}$ & 2,5 \\
Ox(PF $+\mathrm{Zr}^{2}$ actinides) & 12,8 \\
+ Suspension de fines & \\
Oxydes d'actinides & 0,9 \\
\hline Si $\mathrm{O}_{2}+\mathrm{B}_{2} \mathrm{O}_{3}+\mathrm{A}_{2} \mathrm{O}_{3}$ & \\
\hline
\end{tabular}

$\mathrm{SiO}_{2}, \mathrm{~B}_{2} \mathrm{O}_{3}$ and $\mathrm{Na}_{2} \mathrm{O}$ are the major components 


\section{Swelling under irradiation in R7T7 glass}

R7T7 glass has been irradiated internally by ${ }^{244} \mathrm{Cm}$ with different doses and dose rates

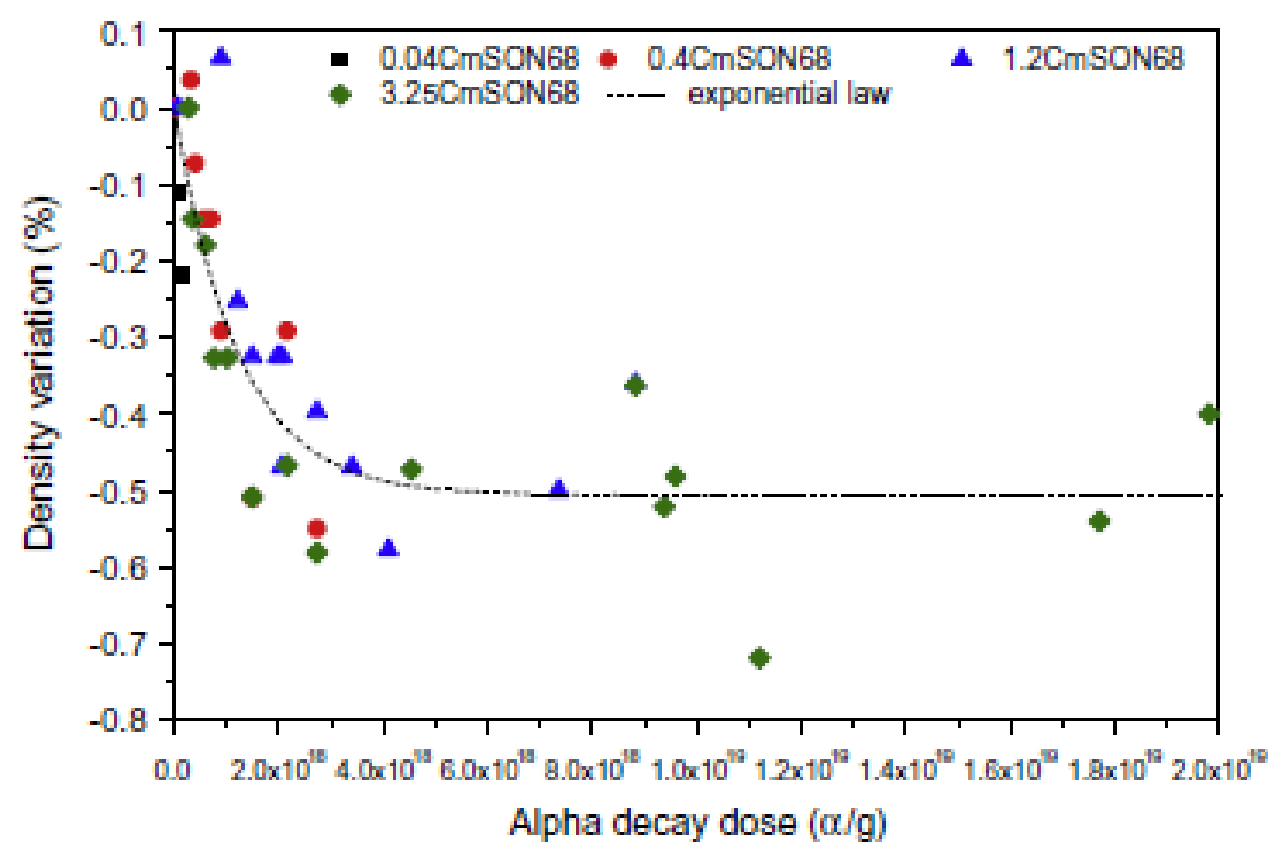

Saturation of the swelling after a critical dose $\left(410^{18} \mathrm{a} / \mathrm{g}\right)$

Final swelling is around $0.6 \%$ for each dose rate

Fig. 1. Density versus alpha decay dose in CmSon68 glass.

S. Peuget et al., J. Nucl. Mater. 444 (2014) 76 


\section{Fracture toughness increase - Hardness decrease}

R7T7 glass has been irradiated externally by heavy ions ( $\mathrm{Kr}, \mathrm{Au})$

Microindentation is used to measure the critical charge $\mathbf{P}_{\mathrm{c}}$ for which the fracture probability is equal to $50 \% \rightarrow$ the fracture toughness can be deduced

$$
P_{c}=A \frac{K_{I C}^{4}}{H^{3}}
$$

Fracture toughness increases by around $25 \%$ in the $\mathrm{R} 7 \mathrm{~T} 7$ glass irradiated by Au ions

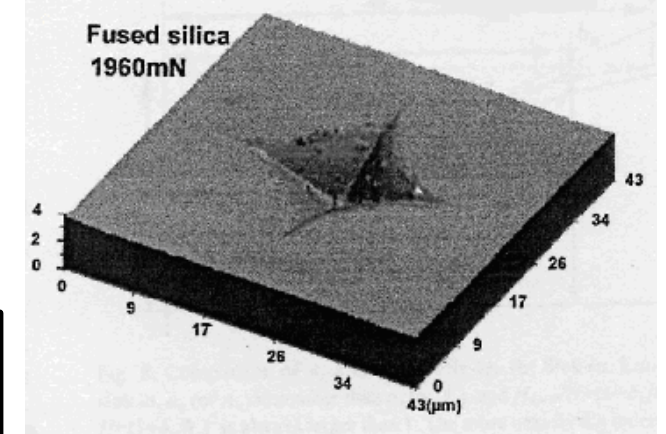

R7T7 glass has been doped by short lived actinides $\left({ }^{244} \mathrm{Cm}\right)$ or irradiated externally by heavy ions (Kr, Au, Si)

Hardness is measured by Vickers micro indentation

Hardness decreases by around $30 \%$ 


\section{Anology between R7T7 glass and simplified glasses: density}

Three simplified glasses have been prepared:

\begin{tabular}{|l|l|l|l|l|l|l|}
\hline$\%$ mol & $\mathrm{SiO}_{2}$ & $\mathrm{~B}_{2} \mathrm{O}_{3}$ & $\mathrm{Na}_{2} \mathrm{O}$ & $\mathrm{Al}_{2} \mathrm{O}_{3}$ & $\mathrm{CaO}$ & $\mathrm{ZrO}_{2}$ \\
\hline SBN14 = CJ1 & $\mathbf{6 7 . 7 3}$ & $\mathbf{1 8 . 0 4}$ & $\mathbf{1 4 . 2 3}$ & - & - & - \\
\hline CJ3 & 61.16 & 16.29 & 12.85 & 3.89 & 5.81 & - \\
\hline CJ7 & 63.77 & 16.98 & 13.39 & 4.05 & & 1.81 \\
\hline
\end{tabular}

Irradiated by $\mathrm{Au}$ ions

The swelling is qualitatively the same as in the R7T7 glass

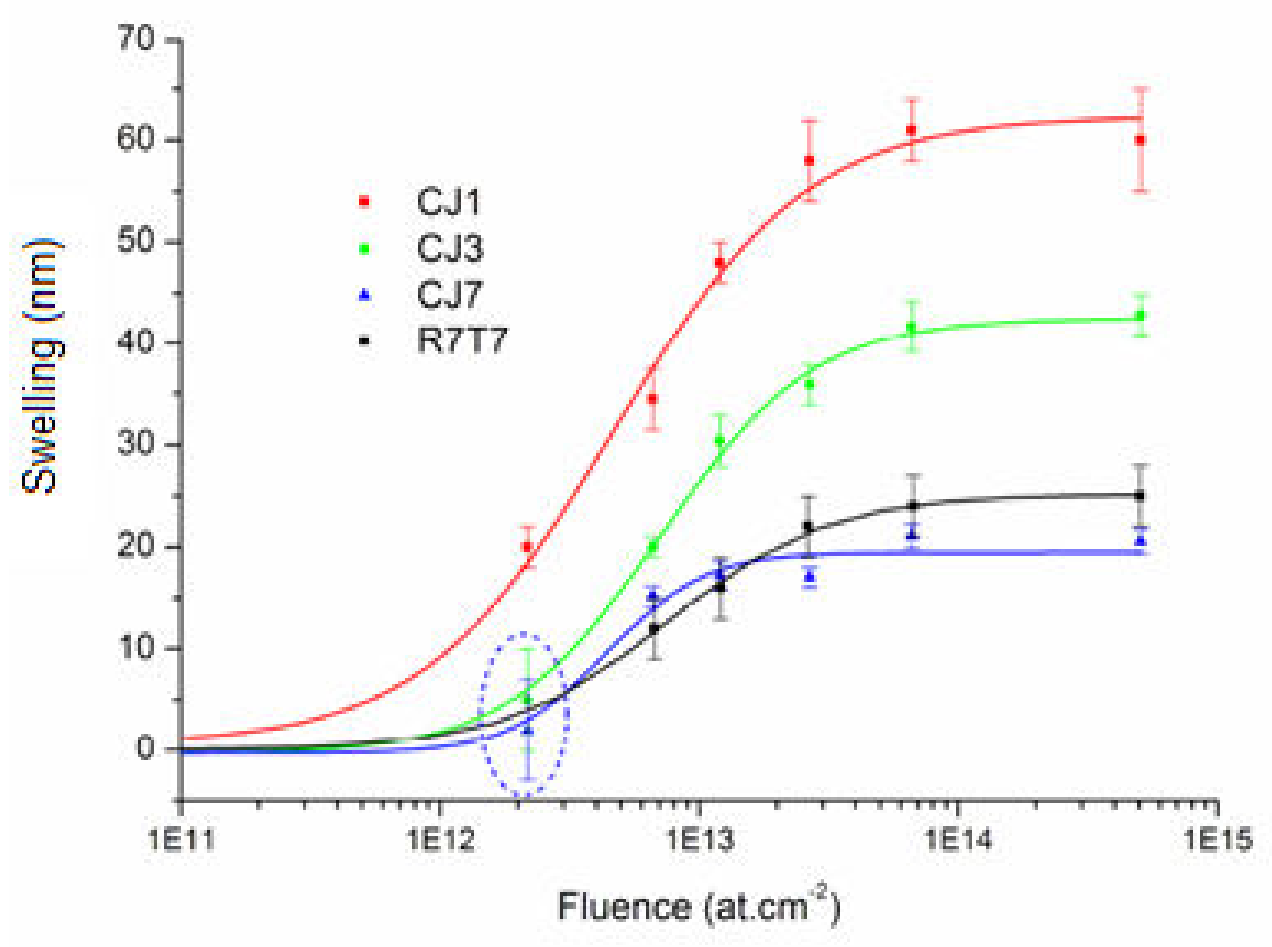

Saturation of the swelling with the dose

The swelling is larger in the simplified glasses 


\section{Anology between R7T7 glass and simplified glasses: fracture toughness and hardness}

Fracture toughness and hardness have been measured in the three simplified glasses (SBN14 = CJ1, CJ3, CJ7) subjected to heavy ion or neutron irradiations

The fracture toughness and hardness changes are qualitatively the same as in the R7T7 glass

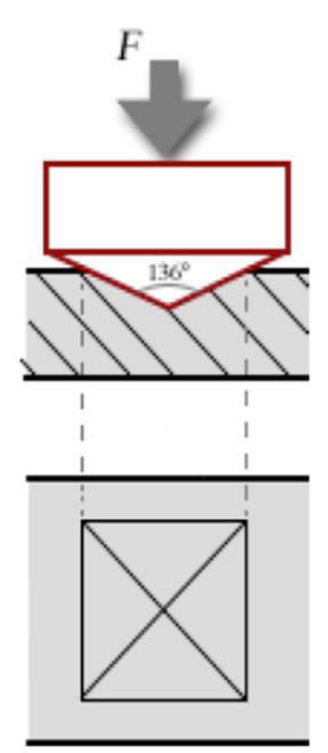

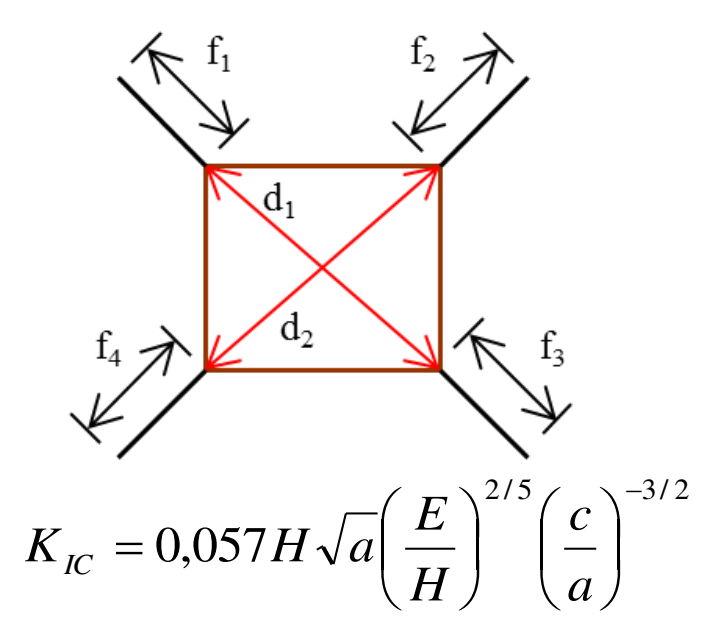

SBN14: Increase of the

fracture toughness

$(+16 \%)$ after

irradiation by neutrons

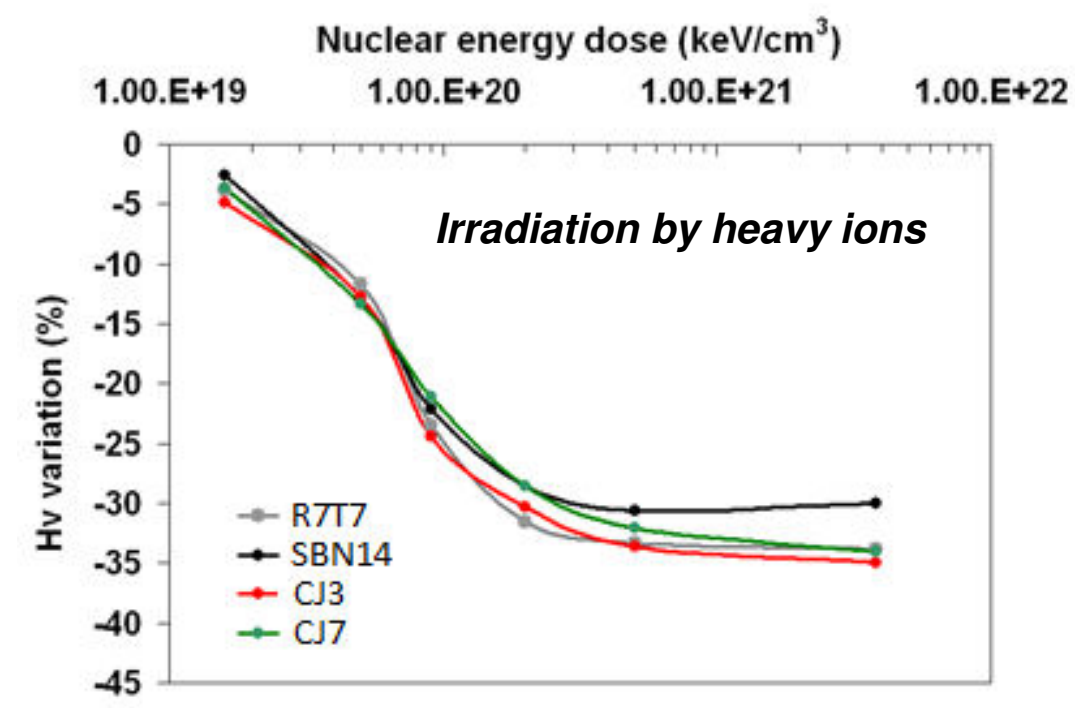

Decrease of the hardness after irradiation by heavy ions 


\section{Use of classical molecular dynamics to investigate the consequences of ballistic effects}

Atomistic modeling of simplified nuclear glasses based on $\mathrm{SiO}_{2}-\mathrm{B}_{2} \mathrm{O}_{3}-$ $\mathrm{Na}_{2} \mathrm{O}$

Objective: To understand the atomistic origin of the swelling, fracture toughness increase and hardness decrease under irradiation

Empirical interatomic potentials are used

- fitted on structural data (Boron coordination, structure factors) and macroscopic properties (density, elastic moduli):

$$
\phi\left(r_{i j}\right)=\frac{q_{i} q_{j}}{r_{i j}}+A_{i j} \exp \left(-\frac{r_{i j}}{\rho_{i j}}\right)-\frac{C_{i j}}{r_{i j}^{6}}
$$




\section{Empirical potentials: macroscopic properties}

A series of simple glasses are simulated to validate the potentials

\begin{tabular}{|l|c|c|c|c|}
\hline \multirow{2}{*}{ Glasses } & \multicolumn{3}{|c|}{ Chemical compositions } & \multirow{2}{*}{ C ${ }_{\mathrm{B}}(\mathrm{Y} \& \mathrm{~B})$} \\
\cline { 2 - 4 } & $\mathrm{SiO}_{2}$ & $\mathrm{~B}_{2} \mathrm{O}_{3}$ & $\mathrm{Na}_{2} \mathrm{O}$ & \\
\hline SB & 69.5 & 30.5 & 0 & $3.01(3.0)$ \\
\hline SBN3 & 48 & 48.7 & 3.3 & $3.09(3.07)$ \\
\hline SBN10 & 44.4 & 46.1 & 9.6 & $3.23(3,21)$ \\
\hline SBN12 & 59.66 & 28.14 & 12.20 & $3.41(3,43)$ \\
\hline SBN14 & 67.73 & 18.04 & 14.23 & $3.72(3,73)$ \\
\hline SBN55 & 55.30 & 14.71 & 29.99 & $3.58(3,62)$ \\
\hline
\end{tabular}
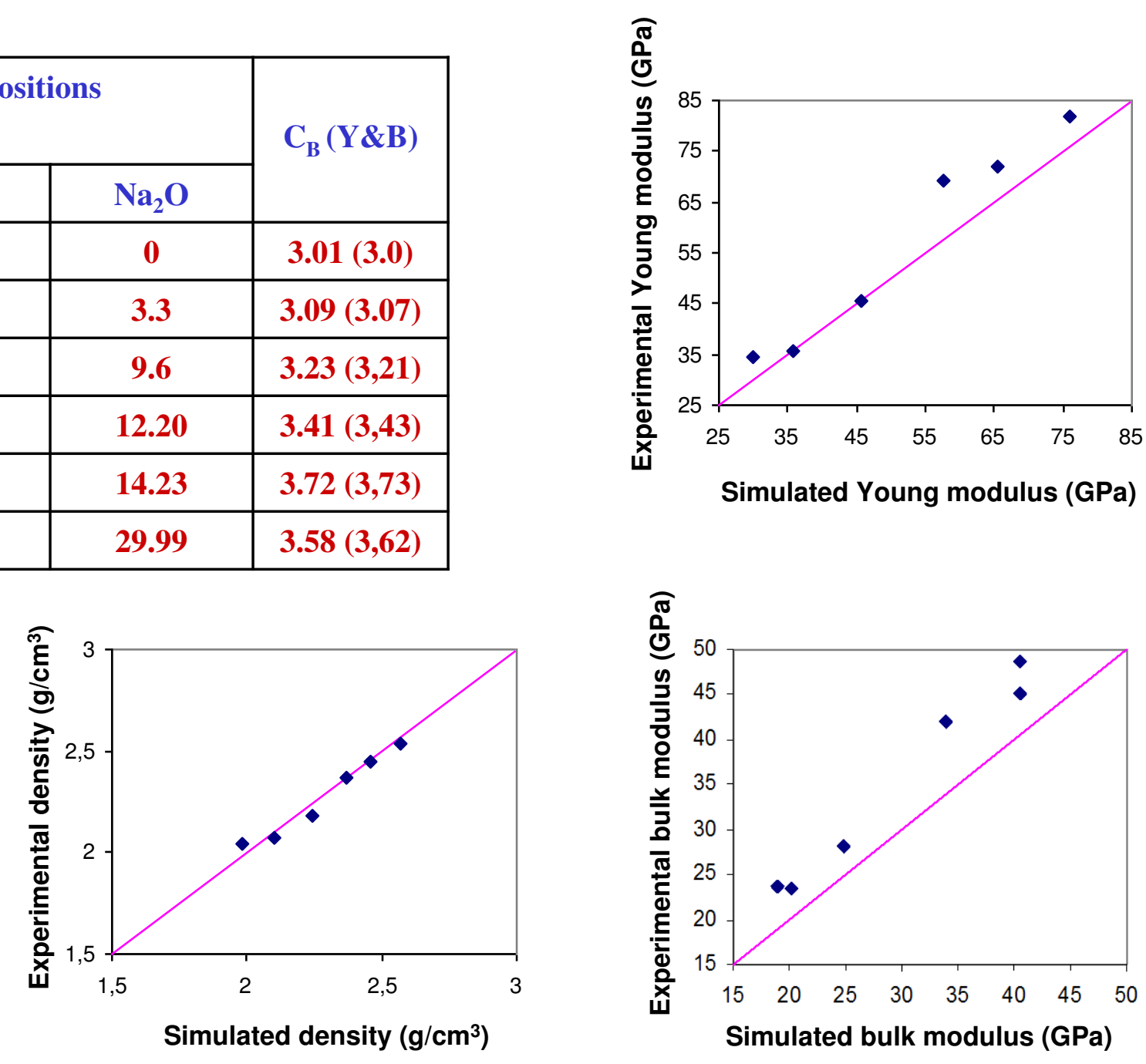

PAGE 9

L.-H. Kieu et al., J. Non-Cryst. Solids 357 (2011) 3313 


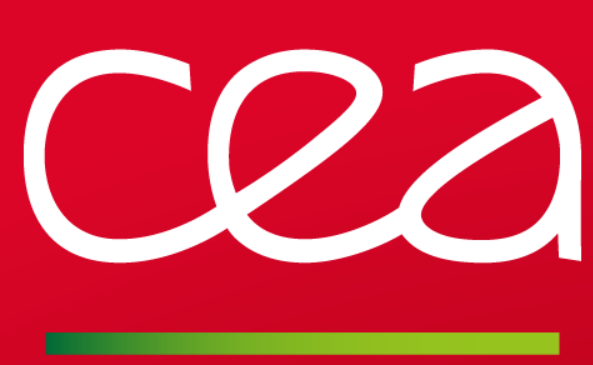

Series of displacement cascades simulated by classical molecular dynamics 
Series of $600 \mathrm{eV}$ displacement cascades have been simulated to completely irradiate the volume

- Swelling under ballistic effects

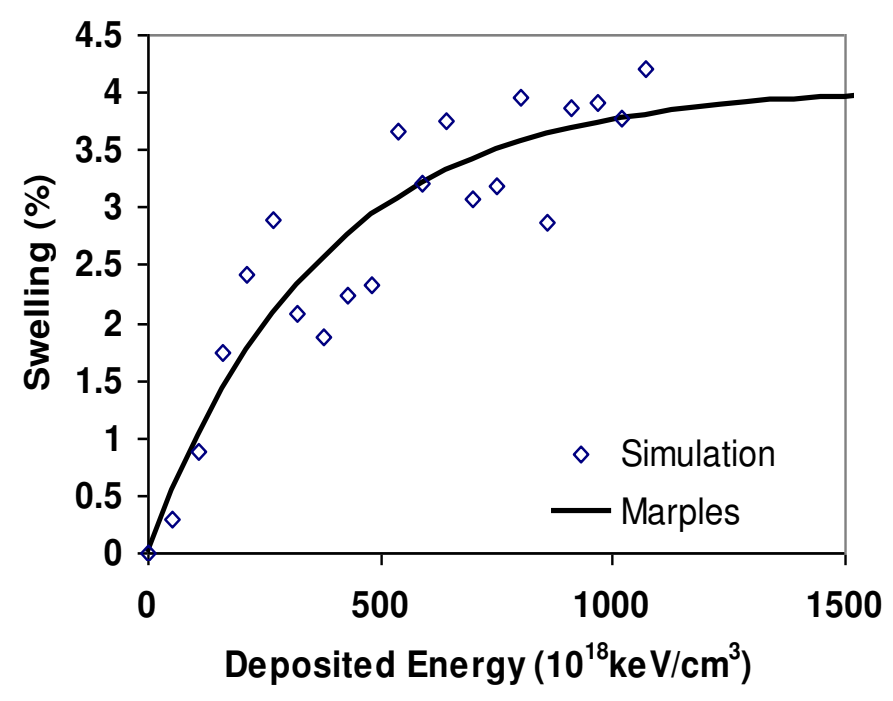

Decrease of the bulk modulus

Bulk modulus decreases from $85 \mathrm{GPa}$ to $61 \mathrm{GPa}(-28 \%)$ (the decrease of the elastic moduli in the real glass is equal to $-30 \%$ )
Equivalence

\begin{tabular}{|l|l|}
\hline $4.010^{20} \mathrm{keV} / \mathrm{cm}^{3}$ & $210^{18} \mathrm{\alpha} / \mathrm{g}$ \\
\hline
\end{tabular}

Experimental swelling in SBN14 irradiated by heavy ions: $\sim 4.0 \%$ Saturation dose: $510^{20} \mathrm{keV} / \mathrm{cm}^{3}$

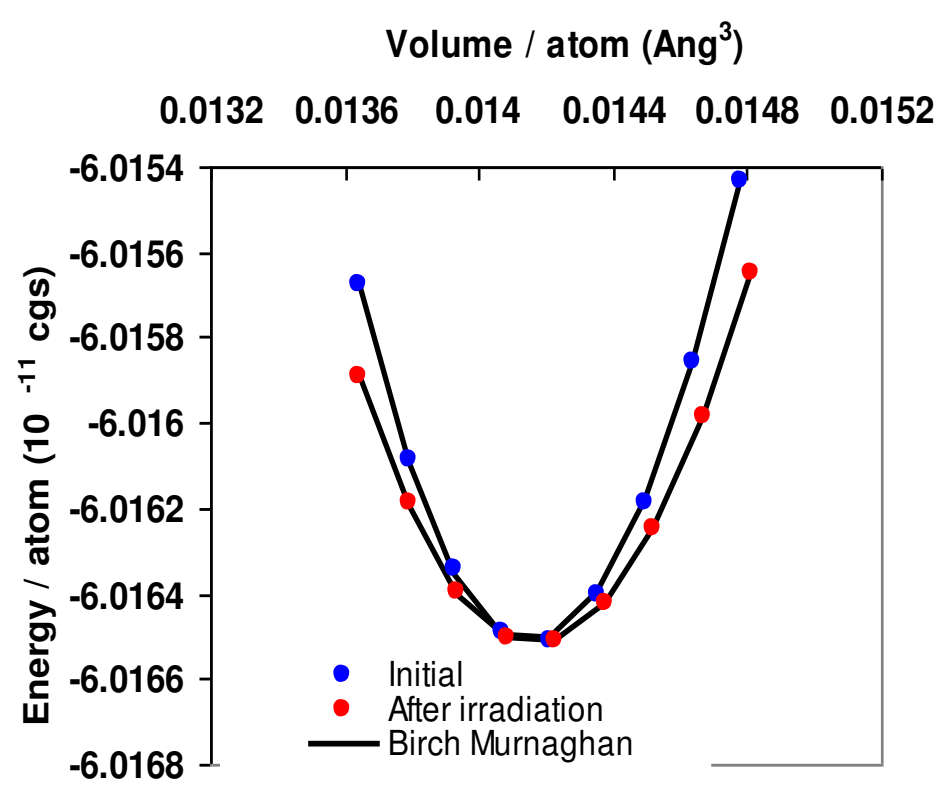




\section{Depolymerization}

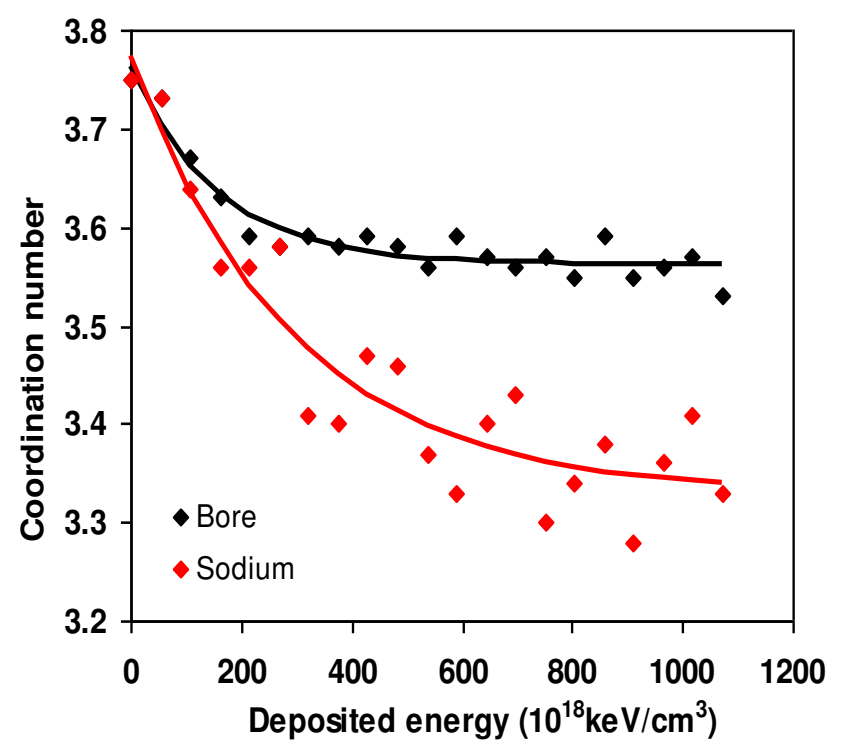

\begin{tabular}{|l|l|l|l|l|}
\hline & $\% \mathrm{~B}^{[3]}$ & $\% \mathrm{~B}^{[4]}$ & $\mathrm{Q}_{4}$ & $\mathrm{Q}_{3}$ \\
\hline Initial & $25 \%$ & $75 \%$ & $\underline{\mathbf{9 5 . 8 \%}}$ & $\underline{\mathbf{4 . 2 \%}}$ \\
\hline Final & $47 \%$ & $53 \%$ & $\underline{\mathbf{8 5 . 2 \%}}$ & $\underline{\mathbf{1 4 . 6 \%}}$ \\
\hline
\end{tabular}
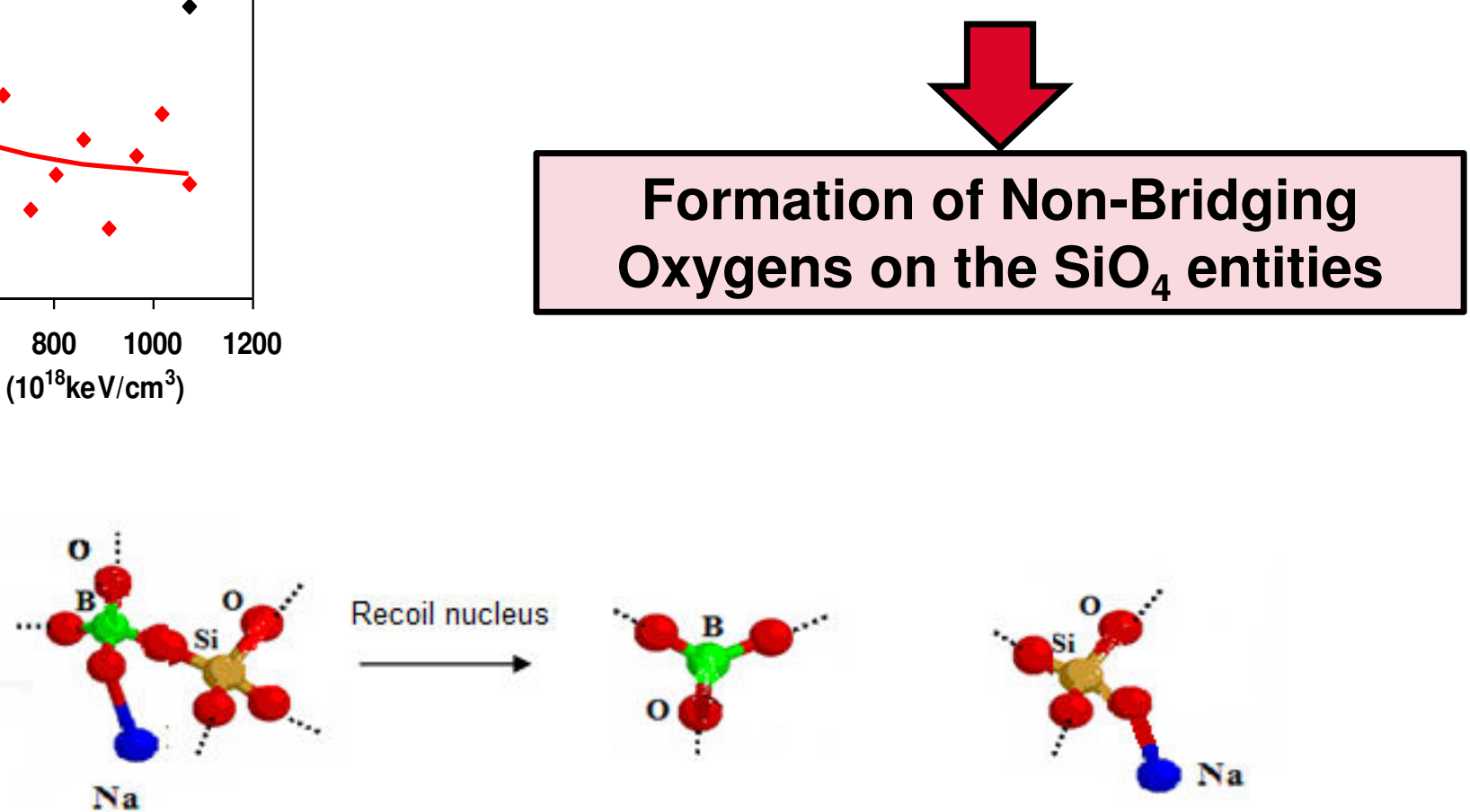
Internal energy increases

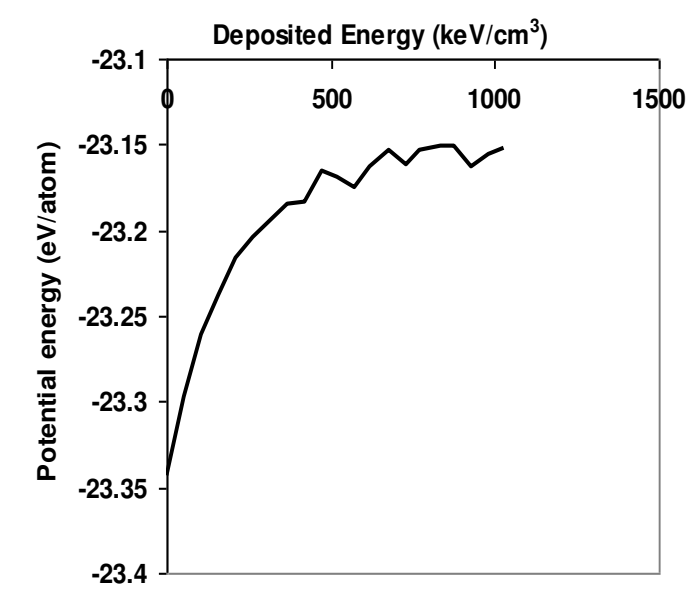

Decrease of Si-O-Si (and Si-O-B) angles

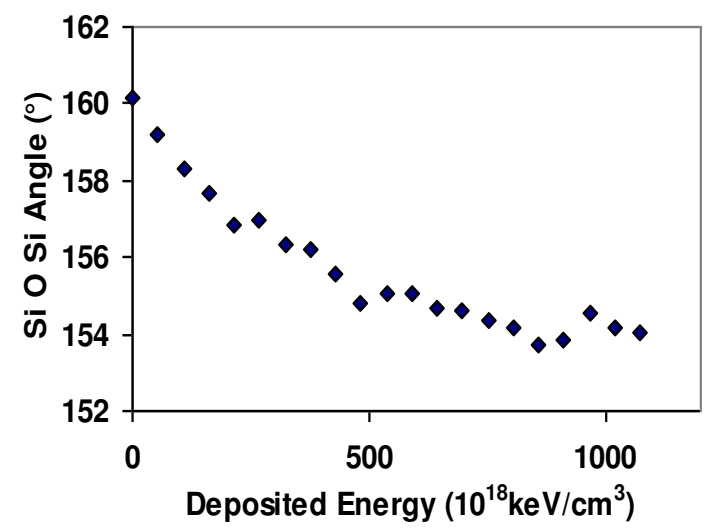

Widening of the distributions
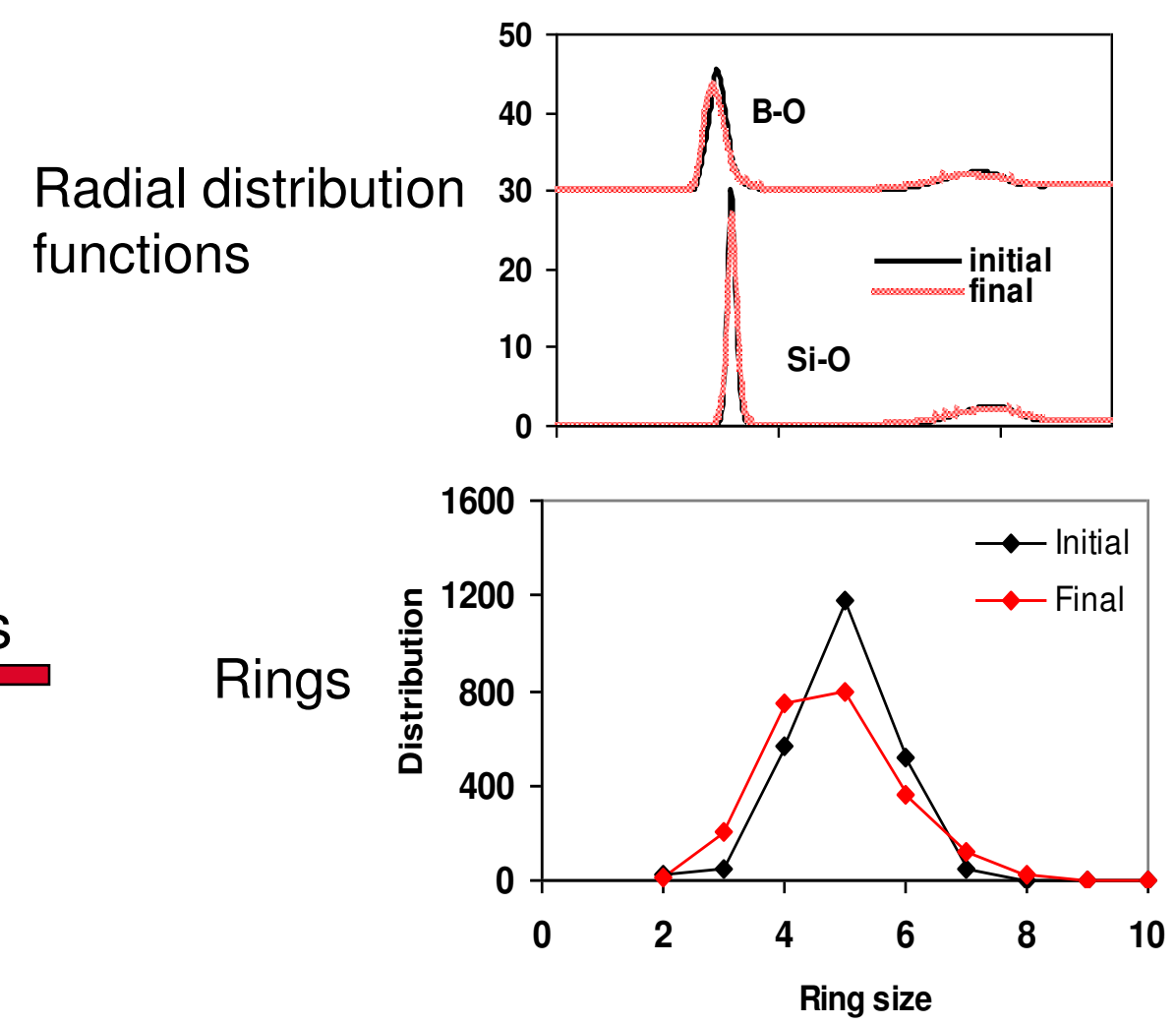


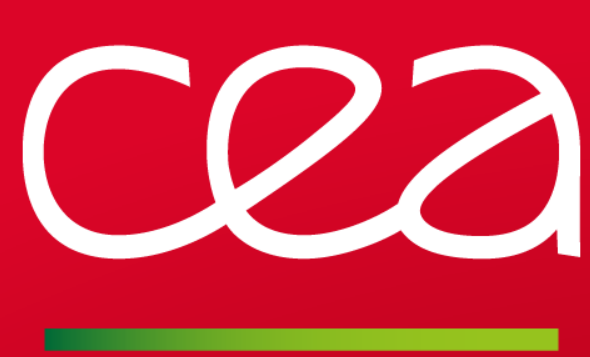

Simulation of fracture behavior by classical molecular dynamics 


\section{Fracturation method}

- Simulation box : rectangular parallelepiped box (105 atoms) of $250 \times 50 \times 100 \AA^{3}$ 3D initial notch : 30Å deep ( $X$ direction), 20A high ( $Z$ direction), Ly (Y direction) 2 layers of frozen atoms (top and bottom)

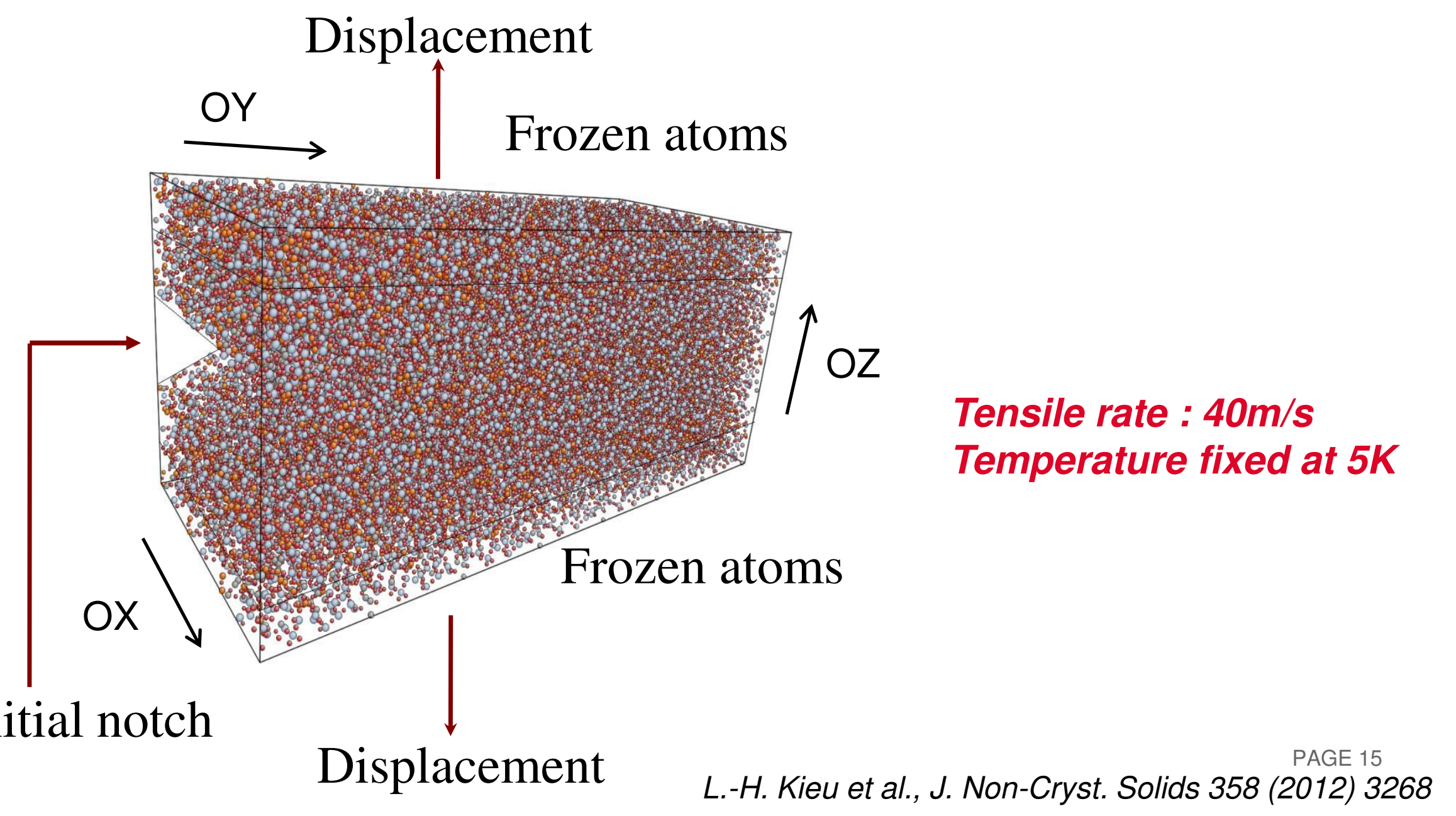




\section{The four steps of fracture mechanisms}

nucleation / Growth / Coalescence / Decohesion (SBN14 glass)
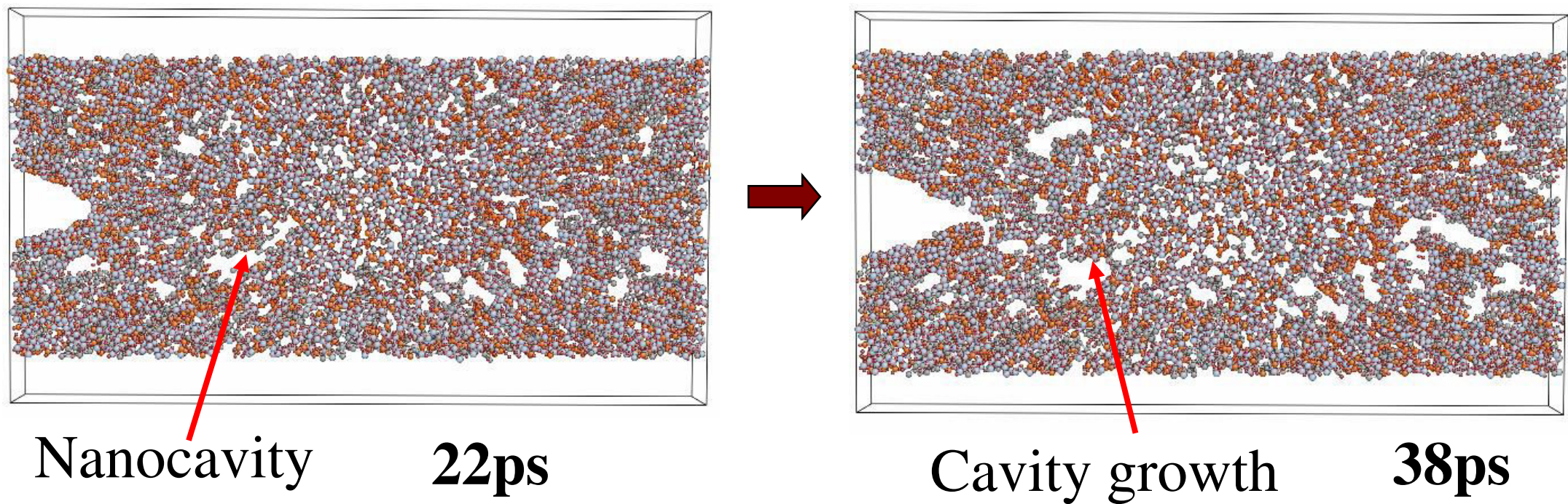

Cavity growth $\quad 38 p s$

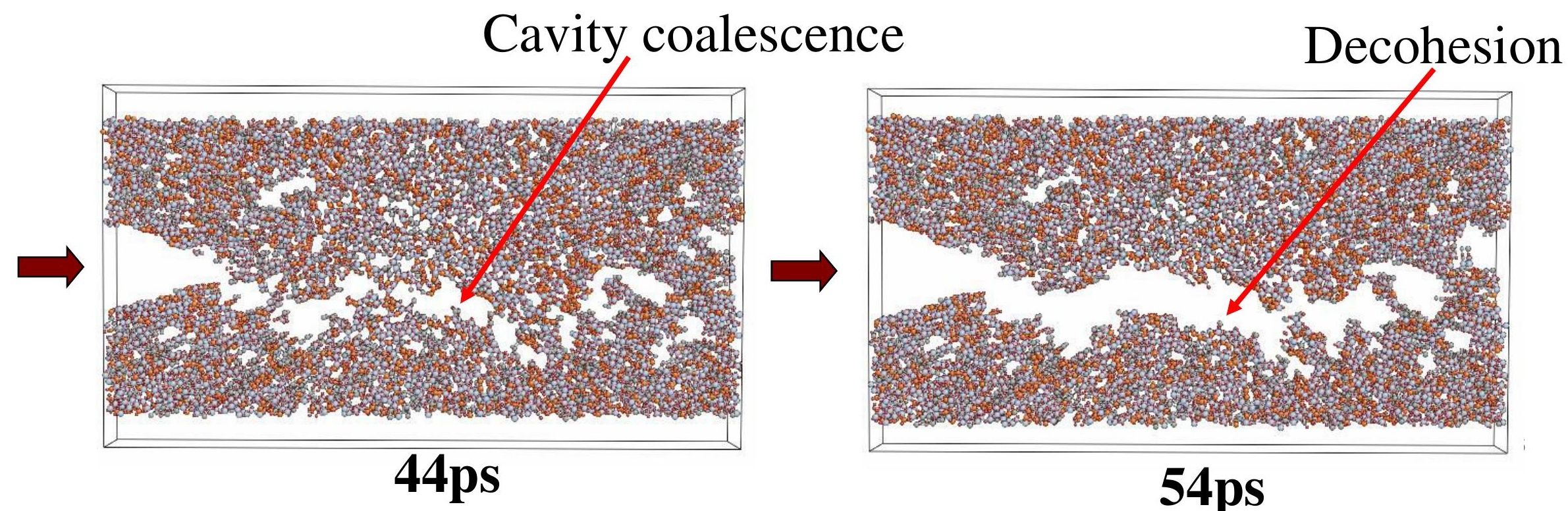




\section{Stress - Strain curves}

E Differences between pristine and disordered SBN14 glass

- Decrease of the Young modulus from 74.0GPa to 51.6GPa (-30\%)

- Decrease of the elastic limit

- Increase of the plasticity region (the non linear part of the stress strain curve): duration from 10ps to $13 p s$

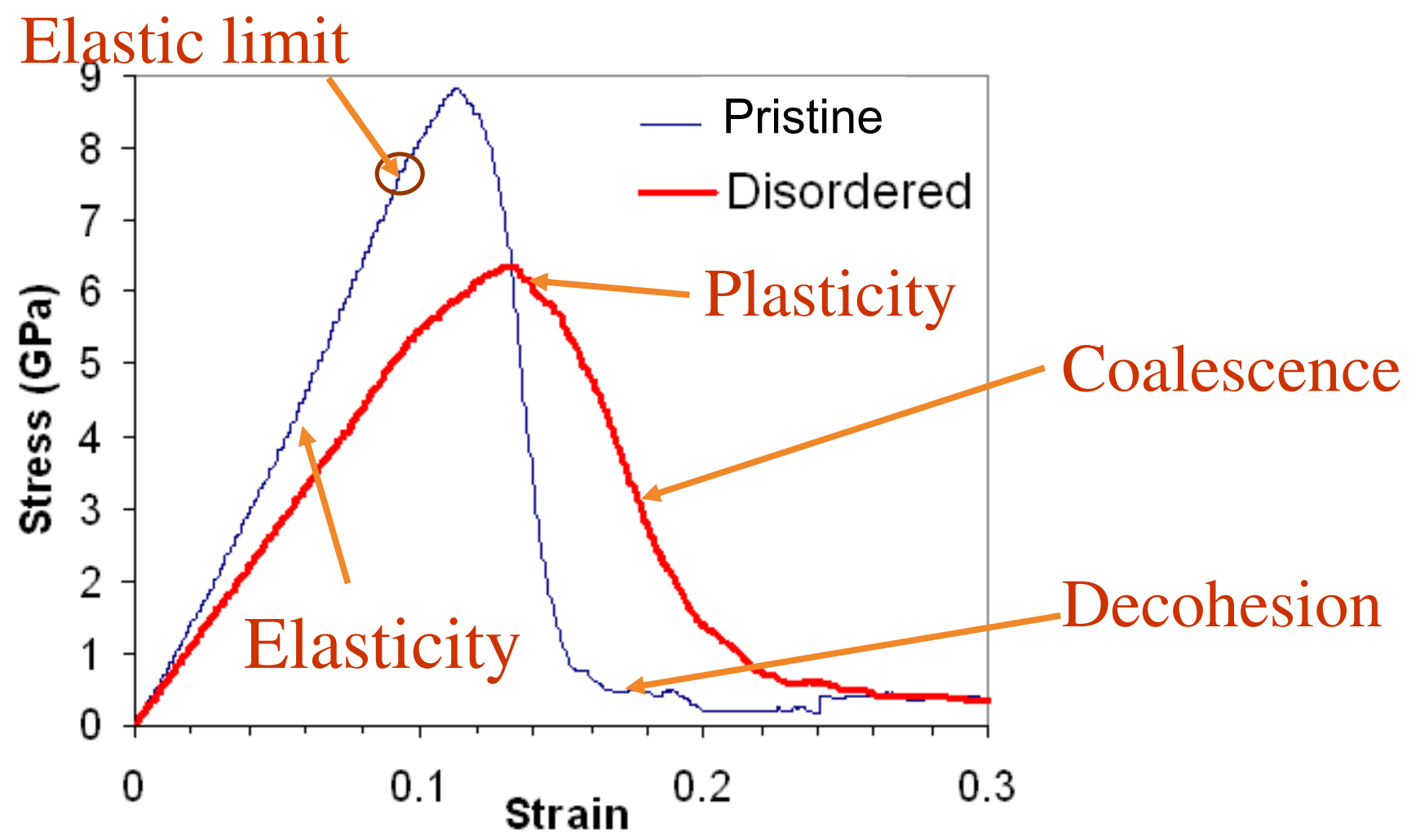




\section{RDFs versus time in the pristine glass: Si-O and ${ }^{[4]} \mathrm{B}-\mathrm{O}$}

- The cations behave differently depending on their local coordination

- Tetracoordinated elements : Si and ${ }^{[4]} \mathrm{B} \rightarrow$ " strong » elements
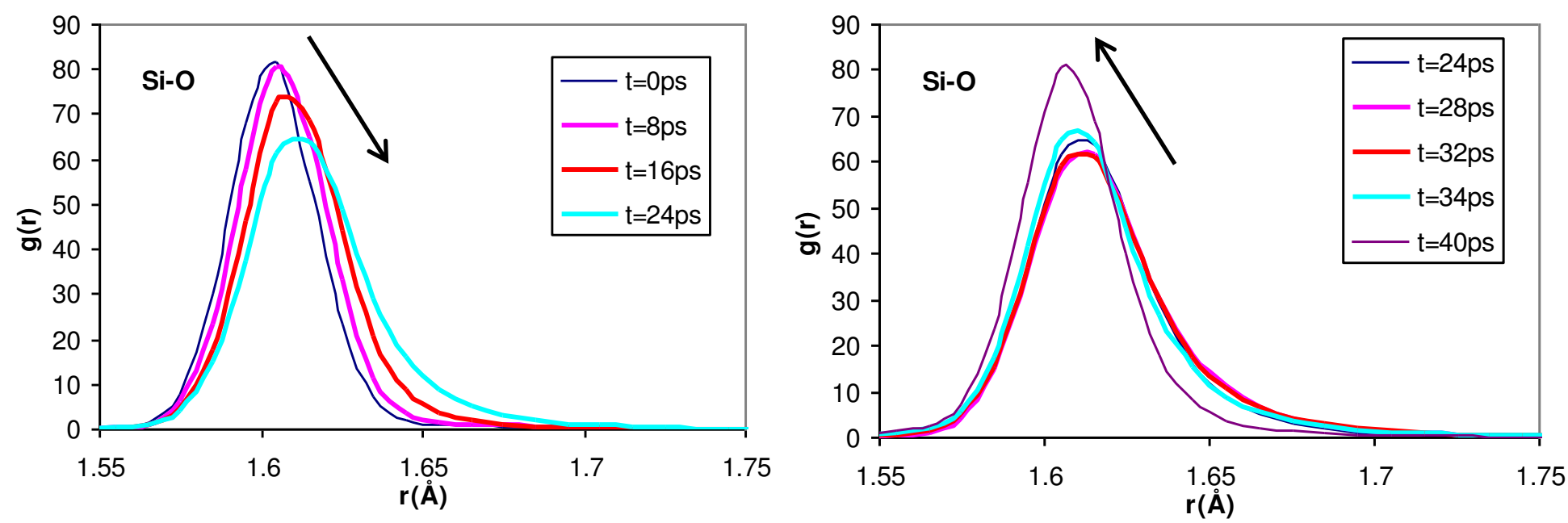

RDF Si-O

0 to $24 \mathrm{ps}$ : Stretching of the $\mathrm{Si}-\mathrm{O}$ and ${ }^{4} \mathrm{~B}-\mathrm{O}$ distances

24 to $40 \mathrm{ps}$ : Relaxation of the $\mathrm{Si}-\mathrm{O}$ and ${ }^{4} \mathrm{~B}-\mathrm{O}$ distances
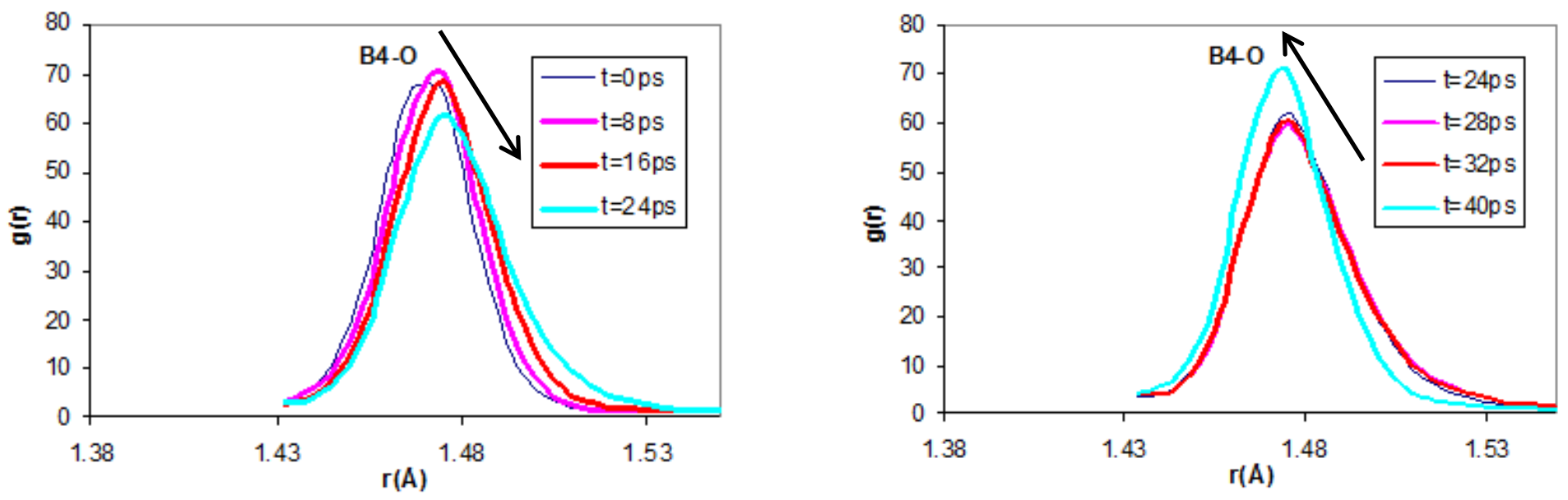

RDF ${ }^{[4]} \mathrm{B}-\mathrm{O}$ 


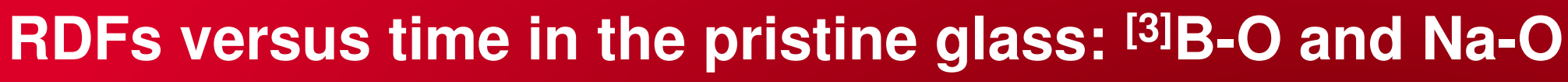

- The cations behave differently depending on their local coordination

$={ }^{3} \mathrm{~B}$ and $\mathrm{Na} \rightarrow$ «Soft » elements
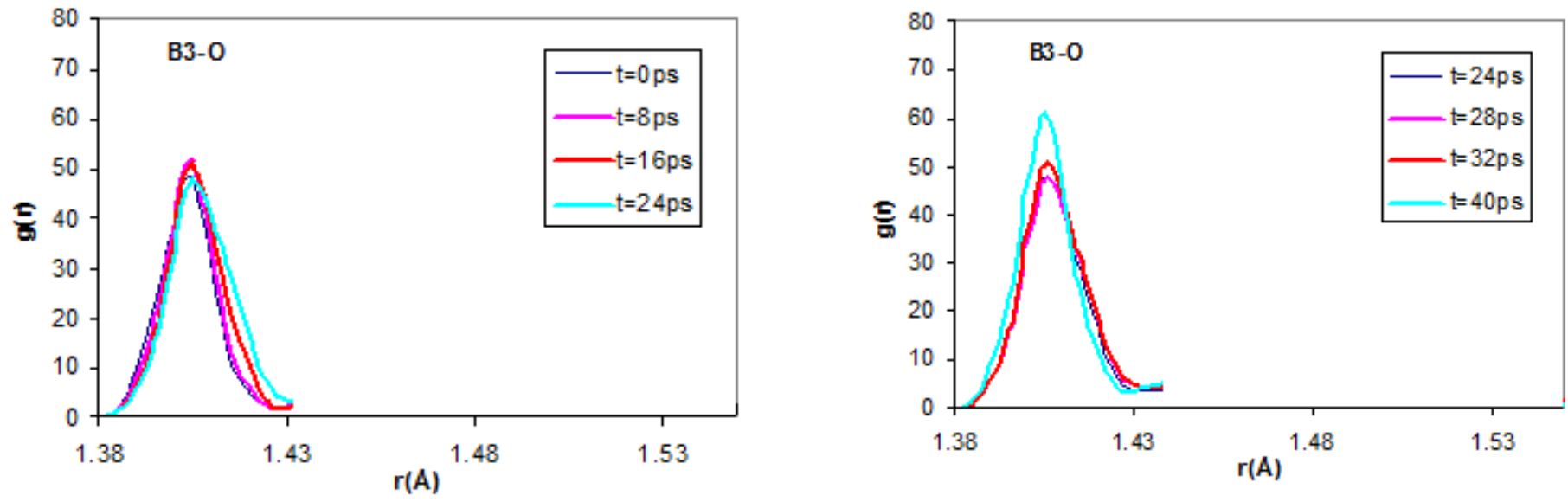

RDF ${ }^{[3] B-O}$

No stretching of ${ }^{3} \mathrm{~B}-\mathrm{O}$ or $\mathrm{Na}-\mathrm{O}$ distances
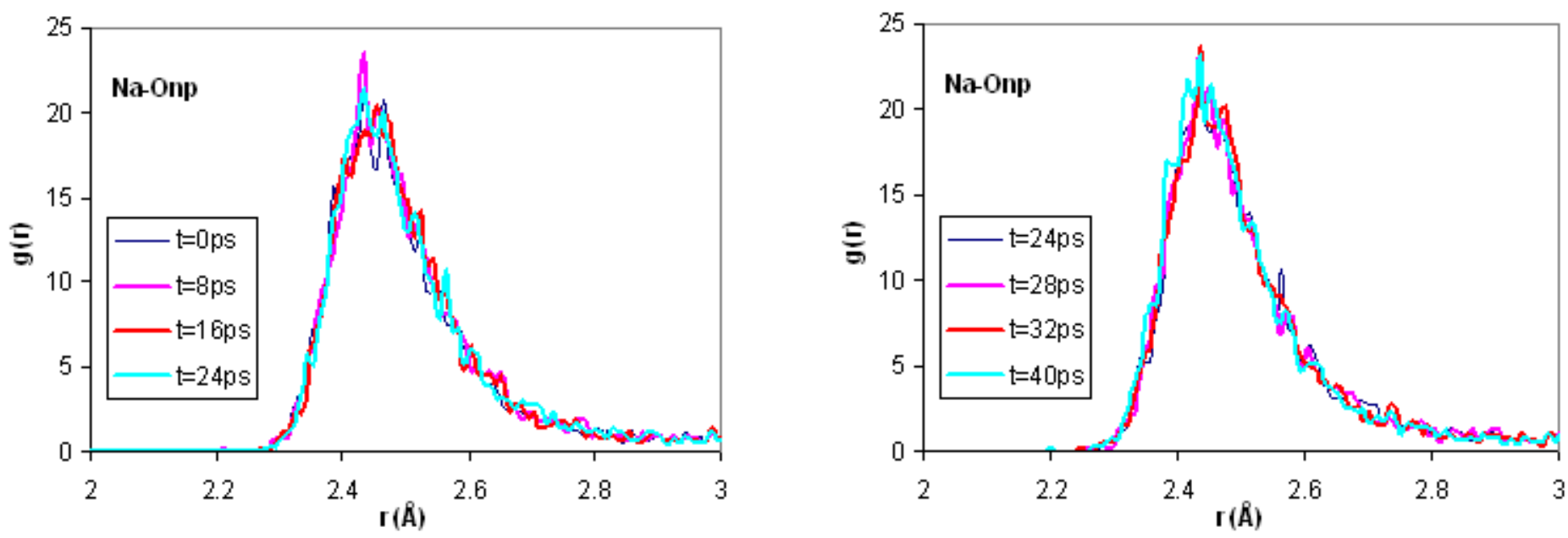

RDF Na-O 
E In the disordered (i.e. irradiated) glasses:

- Increase of the ${ }^{[3]} \mathrm{B}$ relative to the ${ }^{\left[{ }^{[4]} \mathrm{B}\right.}$

$\rightarrow$ it explains why the pastic phase increases in the disordered glass because the ${ }^{[3]} \mathrm{B}$ atoms enhance the plastic processes

- The enhancement of the plastic processes consumes a larger energy

$\rightarrow$ it explains the fracture toughness increase under irradiation 
DE LA RECHERCHE À L'INDUSTRIE

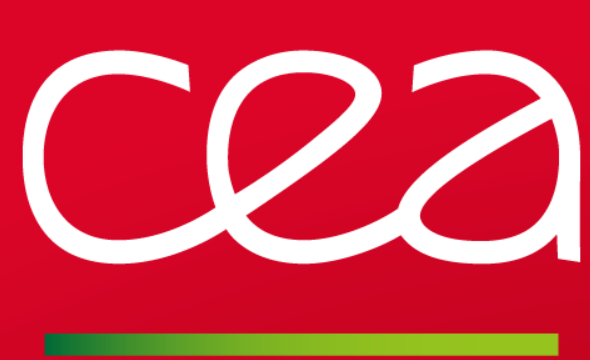

Simulation of nanoindentation by classical molecular dynamics 


\section{Simulation of hardness: Method}

$35 \mathrm{~nm} \times 35 \mathrm{~nm} \times 25 \mathrm{~nm}\left(<>210^{6}\right.$ atoms $)$

Indentation speed : $10 \mathrm{~m} / \mathrm{s}$

- Step of indentation : $0.1 \AA$

Temperature : $300 \mathrm{~K}$

Indentor : Vickers diamond tip (136 apex angle)

At full loading, a 50ps relaxation period is applied by keeping the indenter still

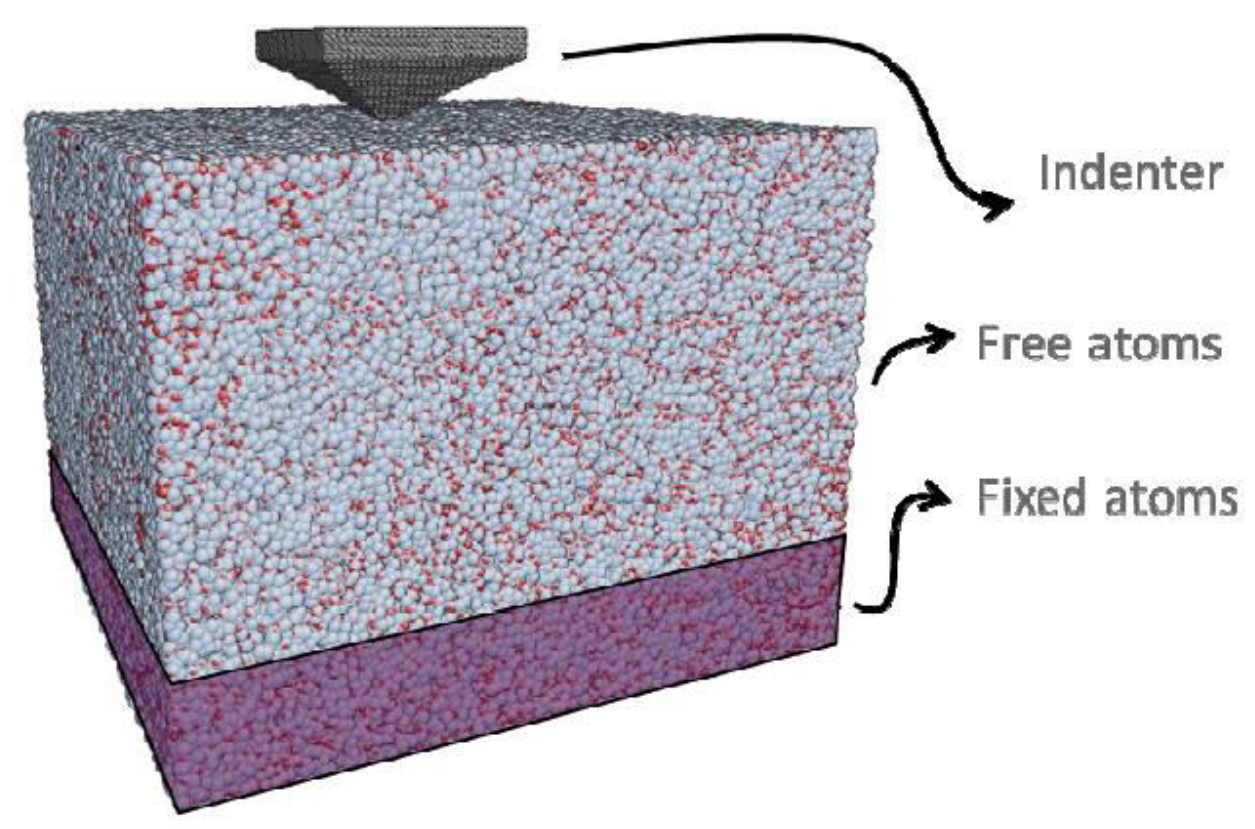

D. Kilymis et al., J. Non-Cryst. Solids 382 (2013) 87 


\section{Simulation of hardness: indentation profiles}

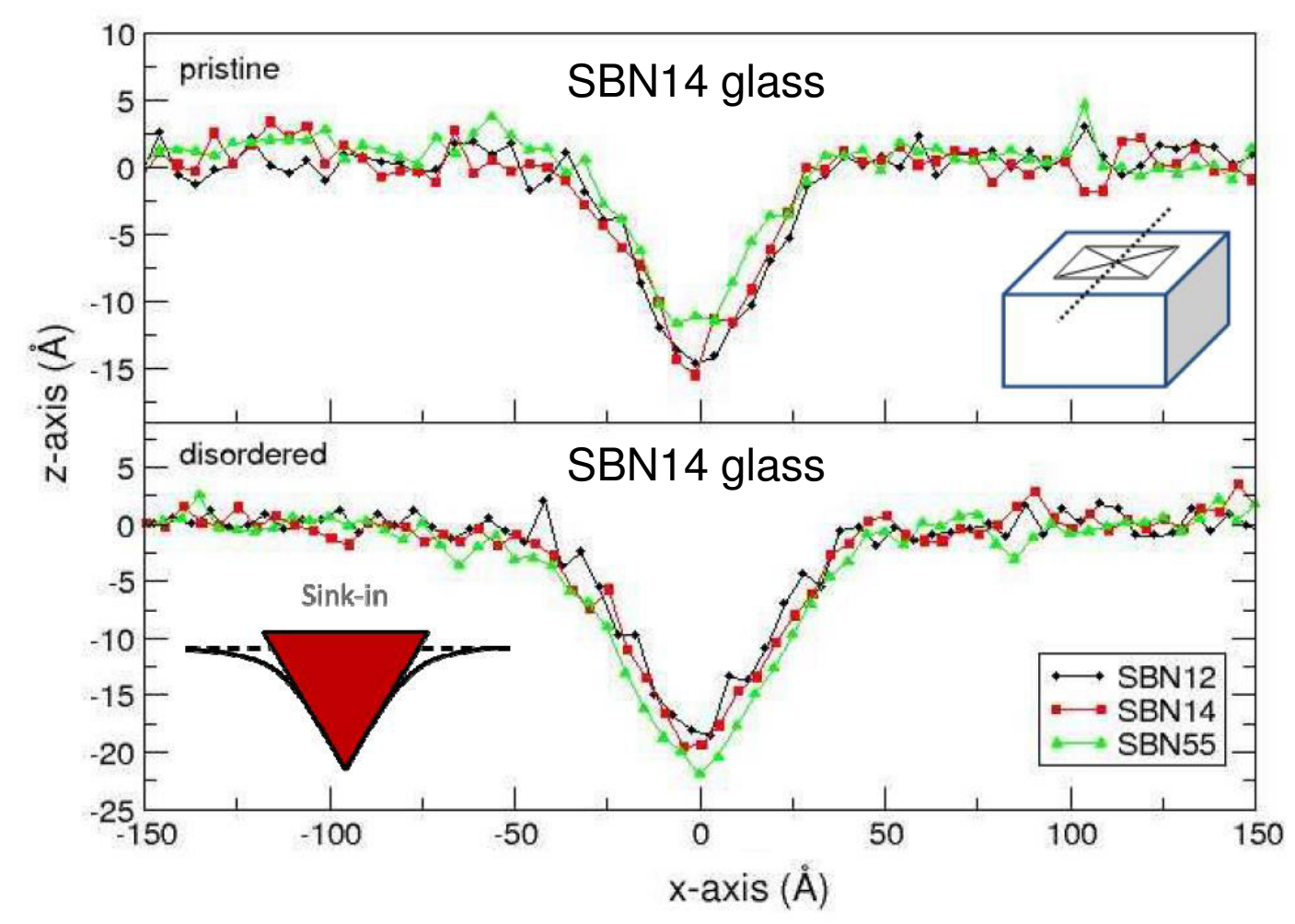

Indentation profiles

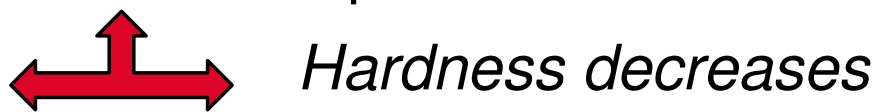

(qualitative observation)

Oliver-Pharr method to determine the contact surface, then the hardness

$$
\begin{gathered}
h_{c}=h_{\max }-\varepsilon \frac{P_{\max }}{S} \\
H=\frac{P_{\max }}{A_{c}}=\frac{P_{\max }}{4 h_{c}^{2} \tan ^{2} \theta}
\end{gathered}
$$

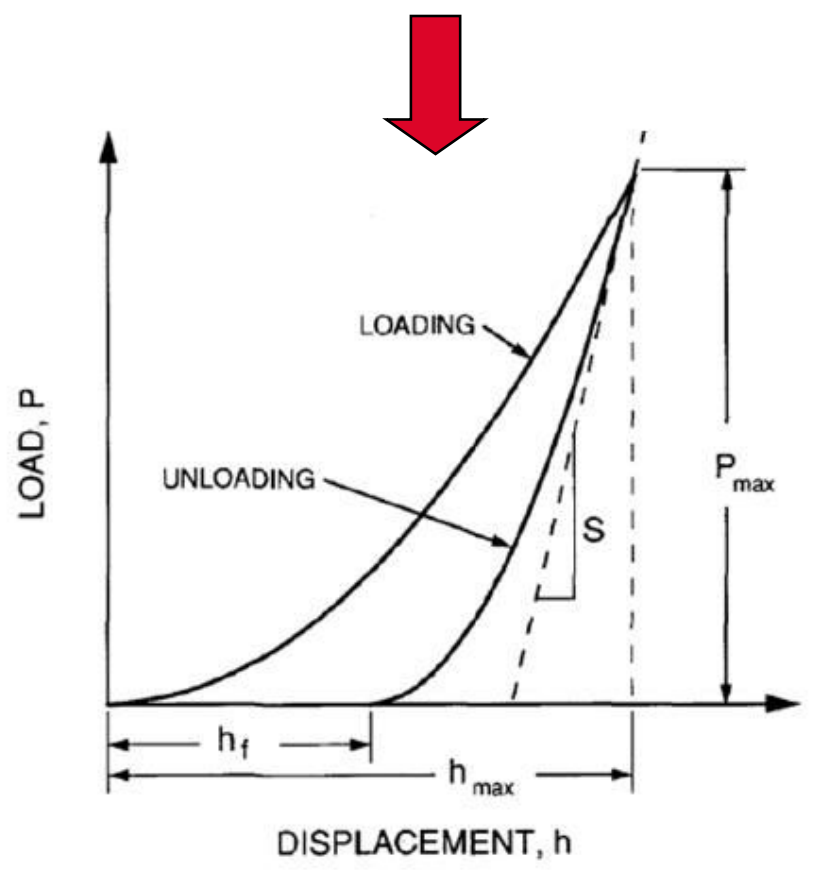




\section{Quantitative hardness measurements}

- Comparison between simulated and experimental values

\begin{tabular}{|c|c|c|c|}
\hline Hardness & $\begin{array}{c}\text { Pristine } \\
\text { (difference with } \\
\text { experimental } \\
\text { value) }\end{array}$ & Disordered & $\begin{array}{c}\text { Experiment } \\
\text { (pristine glasses) }\end{array}$ \\
\hline Silica & $\begin{array}{c}5.5 \mathrm{GPa} \\
4.40 \mathrm{GPa} \\
(-43 \%)\end{array}$ & $-23.4 \%$ & $7.45 \mathrm{GPa}$ \\
\hline SBN12 & $\begin{array}{c}5.45 \mathrm{GPa} \\
(-13 \%)\end{array}$ & $-28.1 \%$ & $6.30 \mathrm{GPa}$ \\
\hline SBN14 & $\begin{array}{c}4.33 \mathrm{GPa} \\
(-15 \%)\end{array}$ & $-42.5 \%$ & $5.1 \mathrm{GPa}$ \\
\hline
\end{tabular}

- Hardness in silica doesn't change much between pristine and disordered structures

- Experimental hardness is better reproduced when the $\mathrm{Na}_{2} \mathrm{O}$ concentration increases

- Hardness decreases in the disordered (i.e. irradiated) SBN14 glass (experimental behavior is reproduced)

D. Kilymis, J.-M. Delaye, J. Non-Cryst. Solids 401 (2014) 147 


\section{Origin of the hardness decrease}

Increase of the hardness with the $\% \mathrm{SiO}_{2}$

Decrease of the hardness in the disordered glasses

Correlations with the $\%{ }^{[3]} \mathrm{B}$ and $\% \mathrm{NBO}$

- Hardness decreases with the $\%{ }^{[3]} \mathrm{B}$

- Hardness decreases with the $\%$ NBO
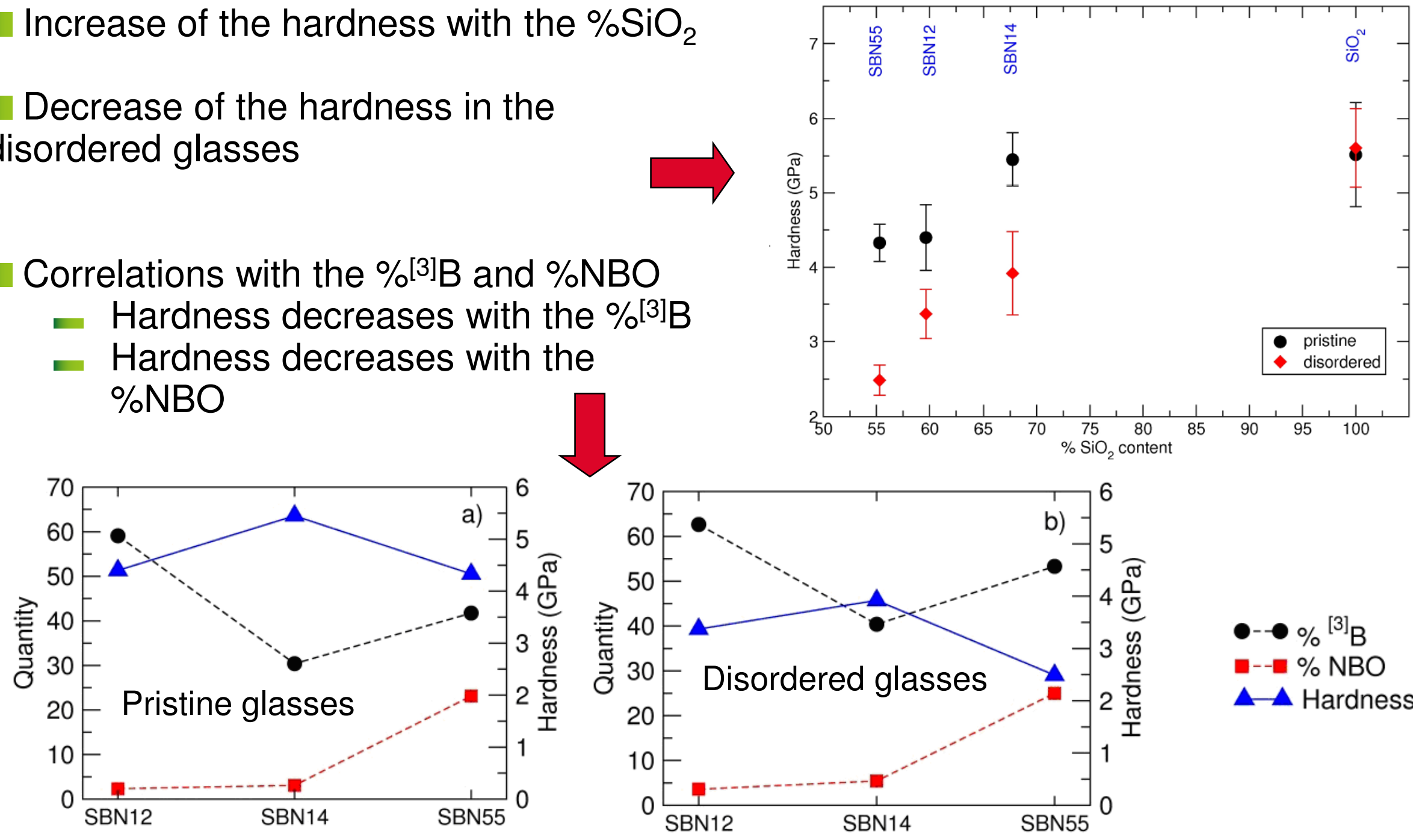

- $-\%{ }^{[3]} \mathrm{B}$

- $\%$ NBO

$\Delta-\Delta$ Hardness

Irradiation: increase of ${ }^{[3]} \mathrm{B}$ concentration and $\% \mathrm{NBO}+$ increase of free volume $\mathrm{e}_{5}$ $\rightarrow$ hardness decrease 


\section{Conclusion}

Experimentally, in the complex and simplified nuclear glasses subjected to ballistic effects:

density decreases, hardness decreases, fracture toughness increases

- Classical molecular dynamics has been used ...

... to simulate displacement cascades in SBN14 glass

swelling is associated with depolymerization and increase of disorder

... to simulate fracture behavior

the increase of the ${ }^{[3]} \mathrm{B}$ concentration favors plasticity $\rightarrow$ origin of the fracture toughness increase

... to simulate nano indentation

the increase of the ${ }^{[3]} \mathrm{B}$ and NBO concentrations facilitates indenter penetration $\rightarrow$ origin of the hardness decrease 


\section{Thanks}

B. Beuneu (LLB), A. Kerrache (CEA Marcoule), L. Cormier (IMPMC): Neutron spectroscopy

M. Barlet (CEA Saclay: DSM / IRAMIS), R. Caraballo, M. Gennisson (CEA Marcoule): Hardness measurements

O. Bouty (CEA Marcoule): WAXS spectroscopy 